\title{
Anemia due to Increased Destruction
}

National Cancer Institute

\section{Source}

National Cancer Institute. Anemia due to Increased Destruction. NCI Thesaurus. Code C131656.

Anemia that results from an increased rate of erythrocyte destruction. 